\title{
Management Background and Release Conditions Structure Post-release Movements in Reintroduced Ungulates
}

\begin{abstract}
Katherine Mertes ${ }^{1 *}$, Jared A. Stabach ${ }^{1}$, Melissa Songer ${ }^{1}$, Tim Wacher ${ }^{2}$, John Newby ${ }^{3}$, Justin Chuven ${ }^{4}$, Shaikha Al Dhaheri ${ }^{4}$, Peter Leimgruber ${ }^{1}$ and Steven Monfort ${ }^{1}$

${ }^{1}$ Conservation Ecology Center, Smithsonian Conservation Biology Institute, Front Royal, VA, United States, ${ }^{2}$ Conservation Programmes, Zoological Society of London, London, United Kingdom, ${ }^{3}$ Sahara Conservation Fund, Bussy-Saint-Georges, France, ${ }^{4}$ Terrestrial and Marine Biodiversity, Environment Agency - Abu Dhabi, Abu Dhabi, United Arab Emirates
\end{abstract}

One of the greatest challenges in restoring species to the wild is insufficient knowledge about their habitat requirements and movement ecology. This is especially true for wide-ranging species such as the scimitar-horned oryx (Oryx dammah). Once widespread across Sahelo-Saharan grasslands, oryx were declared Extinct in the Wild in 1999. Here, we integrate GPS/satellite tracking, remote sensing, and movement analyses to assess how reintroduced oryx respond to wild conditions. We monitored two groups of oryx, reared under different captive management regimes and released in different seasons, for 12 months after release. Our study provides the first movement trajectories and home range estimates for this species. We expected oryx movements after release to represent trade-offs between risky, energetically expensive exploration and resource exploitation. Oryx raised under semi-free ranging conditions and released during the wet season ("ranging") exhibited this pattern of exploration followed by home range establishment. In contrast, oryx raised in small pens and released during the dry season ("penned") explored far less novel terrain. Ranging oryx exhibited seasonal shifts in activity and movement timing, while penned oryx simply reduced overall movement and continuously accessed supplemental food and water. Sahelian ecosystems exhibit strong seasonal cycles and extensive spatial variation. In this highly variable environment, reintroduced oryx will need to disperse from the release site to acquire adequate forage throughout the year. Thus, we experimentally varied acclimation period, and expected dispersal to decrease with acclimation period length. Post-release dispersal ranged from 2 to $90 \mathrm{~km}$ : ranging oryx acclimated for ca. 6 months moved 40-60 km from the release site, while penned oryx acclimated for ca. 1 month remained within $5-25 \mathrm{~km}$. Our results demonstrate that captive management and environmental conditions at release strongly influence the extent to which reintroduced oryx disperse and adapt to wild conditions. We also show that-in contrast to previous studies-longer acclimation periods do not necessarily lead to site fidelity. Finally, our findings demonstrate the importance of tracking a large proportion of reintroduced individuals to (1) accurately record post-release behaviors and vital rates, and (2) adaptively evaluate pre- and post-release management actions to improve conservation outcomes.

Keywords: scimitar-horned oryx, ungulate, reintroduction, exploratory movements, dispersal, movement 


\section{INTRODUCTION}

The scimitar-horned oryx (Oryx dammah; hereafter "oryx") is a large African antelope adapted to the arid, seasonal grasslands surrounding the Sahara Desert (Newby, 1978, 1980; Morrow et al., 2013). Once numbering in the hundreds of thousands, oryx ranged across the Sahel from Mauritania to Sudan, performing extensive seasonal migrations across the region (Newby, 1978; Harris et al., 2009). Overhunting, political and military conflicts, habitat degradation and fragmentation, and increased competition with livestock collectively contributed to its decline (Dixon et al., 1991). The last sightings of wild oryx occurred in the late 1980s (Newby, 1988) and oryx were officially classified as Extinct in the Wild in 1999 (Hilton-Taylor, 2000). Fortunately, large numbers survived in private collections and zoological institutions around the world. This captive population, currently estimated at 10,000-15,000 individuals, now functions as a source population for restoring the species to the wild.

To date, oryx have been released into several small (100 ha-100 $\mathrm{km}^{2}$ ) fenced protected areas, including Sidi Toui National Park, Bou Hedma National Park, and Oued Dekouk Nature Reserve in Tunisia; Souss-Massa National Park in Morocco; and North Ferlo in Senegal (Kacem et al., 1994; Beudels et al., 2005). Some of the most favorable areas for reintroducing oryx-sites within the species' historical range where large populations were once observed-exist in the Central African nation of Chad. Following a stakeholder workshop in 2012, the 93,000-km² Ouadi Rimé-Ouadi Achim Wildlife Reserve (OROAWR; occasionally referred to as the OROAGR) was identified as an ideal location for reintroduction (Figure 1). Subsequent field work and remote sensing analyses of land cover and precipitation trends (Freemantle et al., 2013) confirmed that the OROAWR will likely maintain a suitable habitat for reintroduced oryx over the long term. Driven by the Environment Agency-Abu Dhabi (EAD), the Chadian Ministère de l'Environnement, de l'Eau et de la Pêche (MEEP), and the Sahara Conservation Fund (SCF), releases of oryx into the OROAWR were initiated in 2016.

Reintroductions and translocations are popular conservation tools to re-establish threatened, endangered, or even extinct species (Seddon et al., 2007; Armstrong and Seddon, 2008; Taylor et al., 2017). However, even after three decades of active research and hundreds of publications, reintroduction efforts remain uncertain ventures that do not necessarily result in viable populations (Griffith et al., 1989; Wolf et al., 1996; Fischer and Lindenmayer, 2000; Godefroid et al., 2011; Ewen et al., 2014). Based on surveys of reporting organizations, Griffith et al. (1989) found that $<50 \%$ of reintroductions of avian, mammal, and fish species were deemed successful. A multi-method analysis by Beck et al. (1994) found that only $11 \%$ of surveyed reintroduction projects met general, conservative criteria for success. A later global analysis by Fischer and Lindenmayer (2000) estimated that success $(26 \%)$ and failure (27\%) occur roughly equally in reintroductions with significant monitoring. Recent efforts to reintroduce large herbivores have been similarly variable: only 4 of 17 bighorn sheep reintroductions in Utah have been successful (Shannon et al., 2008), while $60 \%$ of elk reintroductions in eastern

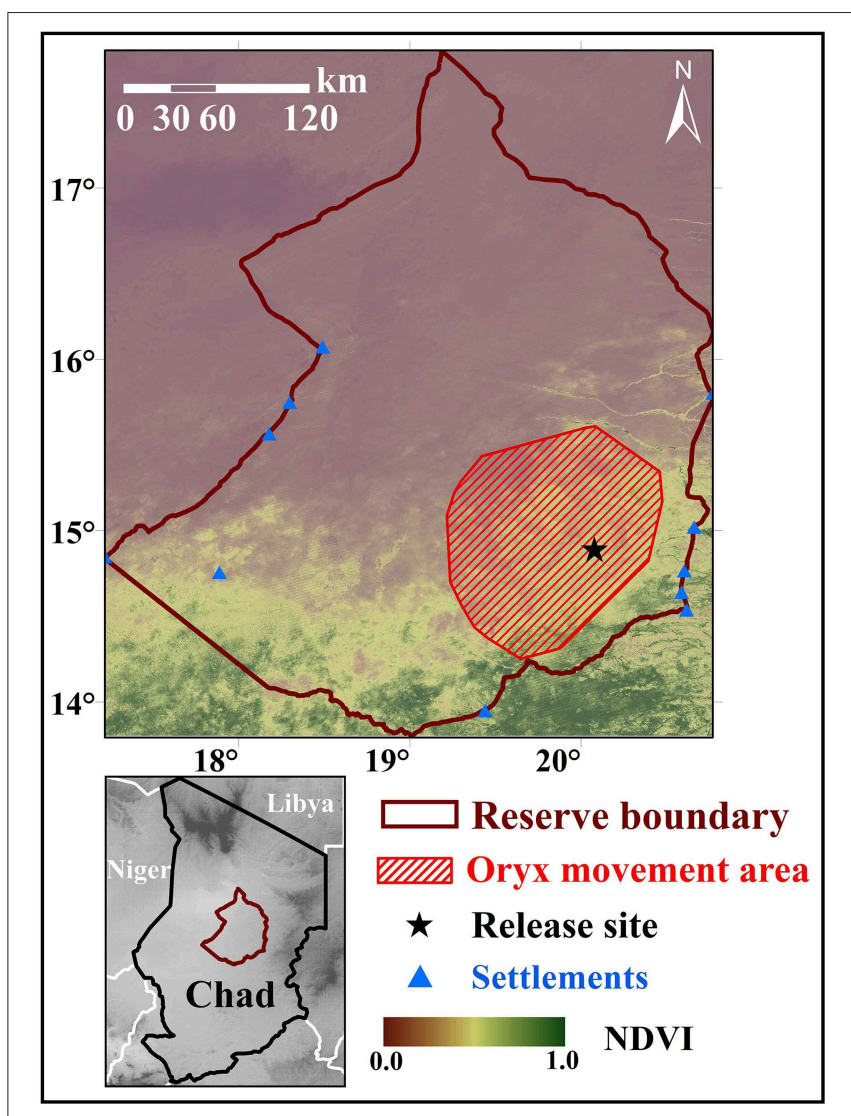

FIGURE 1 | Map of the study site. Primary map shows the study site, the Ouadi Rimé-Ouadi Achim Wildlife Reserve (OROAWR), the spatial context of the release site, and the area that reintroduced scimitar-horned oryx have traversed since August 2016. Background of primary map shows median NDVI during the wet season (July-December, annually) from 2013 to 2018, calculated from MODIS data. Several human settlements exist near the OROAWR border, but no permanent settlements are permitted inside the protected area. Inset map shows the location and elevational context of the OROAWR within the Central African nation of Chad.

North America have resulted in viable populations (Popp et al., 2014).

The (re-)establishment of a fully independent and selfsustaining population depends on a variety of inter-connected factors, including habitat suitability, demographics and genetics of the release population, management protocols, threats to reintroduced animals, and public support (Sarrazin and Barbault, 1996; Wolf et al., 1996; Seddon, 1999). Cooperation and involvement of communities near release sites is often critical, since these groups have high potential to impact, and be impacted by, the reintroduced species. Regrettably, information about reintroduction efforts is highly fragmented among scientific journal articles, book chapters, technical reports, newsletters, and popular articles (Seddon et al., 2007; Armstrong and Seddon, 2008). Moreover, the outcomes of more than half of all reintroductions are unknown due to inadequate monitoring (Fischer and Lindenmayer, 2000). The latter statistic is particularly striking because monitoring costs 
typically represent a small fraction of a reintroduction budget, yet generate critical benefits such as estimates of vital rates in reintroduced populations, which can be used to adaptively assess management approaches and evaluate overall success. Consequently, intensive, long-term monitoring activities are considered best practices for modern reintroduction programs (Muths and Dreitz, 2008).

Other emerging best practices for reintroductions include moving past post-hoc interpretations of outcomes and toward more rigorous deductive and experimental methods (Seddon et al., 2007; Sutherland et al., 2010). For example, Ellis et al. (2000) compared reintroduced Mississippi Sandhill cranes reared by parents or humans, determined that rearing method significantly affected post-release survival, and revised reintroduction protocols to emphasize hand-rearing. In another experimental approach, Armstrong et al. (2007) manipulated the quality, availability, and distribution of supplemental food provided to reintroduced hihi in New Zealand, and evaluated the effect by monitoring population vital rates. Experiments designed to test hypotheses or evaluate management alternatives can provide insights into the ecology of the study species and test specific variables that may influence reintroduction success (Sheean et al., 2012; Kemp et al., 2015).

We expected reintroduced scimitar-horned oryx to behave similarly to other large mammals released into large, unfenced areas of suitable habitat: exploration, followed by establishment of a stable home range (Schmitz et al., 2015; Bleisch et al., 2017). Newly released animals often exhibit sporadic movements (Moehrenschlager and Macdonald, 2003; Rittenhouse et al., 2007; Hester et al., 2008; Schmitz et al., 2015), perhaps due to naivety to their environment, the absence of conspecifics that might otherwise guide resource selection, or elevated stress (Dickens et al., 2010; Mihoub et al., 2011). Thus, we expect reintroduced oryx to engage in wide-ranging exploratory movements immediately after release-especially during the wet season, when resources are abundant. Yet, exploration decreases the time available for foraging, vigilance, and reproduction (Moehrenschlager and Macdonald, 2003; Hamilton et al., 2010; Ryckman et al., 2010), and movements through unfamiliar territory are risky in terms of energetic demands, predation risk, and missed opportunities (Yoder et al., 2004; Stamps et al., 2005; Stamps and Swaisgood, 2007; Bonte et al., 2012). Exploration is even more risky when resources are scarce (Stamps et al., 2005; Stamps and Swaisgood, 2007; Mihoub et al., 2011; Bonte et al., 2012). Thus, we expect oryx released during the dry season to exhibit more conservative exploratory movements. To survive over the long term, however, animals must gather sufficient information about the spatiotemporal distribution of critical resources. This is particularly true in Sahelian grasslands and savannas, where animals must obtain adequate resources throughout strong temporal and spatial environmental variation, including periods of extreme heat and drought. As reintroduced oryx become more familiar with the landscape, we expect less risky strategies-such as home range residence or seasonal migration-to emerge.

We also expect longer periods of in situ acclimation to lead to high site fidelity, or a tendency for released animals to remain near the release site (Parker et al., 2008; Tuberville et al., 2008; de la Luz Martinez-Garcia, 2009; Ryckman et al., 2010; Yott et al., 2011). Bleisch et al. (2017) found that 6 months after release, $83 \%$ of elk held for 129-163 days before reintroduction to the Missouri Ozarks remained within $10 \mathrm{~km}$ of their release site. Similarly, Ryckman et al. (2010) found that elk reintroduced into Ontario, Canada, that were held for short periods (4-11 days) dispersed relatively far from release site $(22.6-26 \mathrm{~km})$, while most elk (70\%) held for longer periods (17-112 days) remained near the release site $(7.3-17.5 \mathrm{~km})$. Post-release dispersal was also strongly negatively related to the length of the "soft release" period in reintroduced Key deer (Parker et al., 2008). Site fidelity is often considered favorable in reintroductions, because release sites are carefully located in optimal conditions, while dispersal from this setting exposes reintroduced individuals to greater risk. However, the variable nature of the OROAWR will ultimately require reintroduced oryx to disperse from the release site to acquire adequate forage throughout the year. Given these constraints, we experimentally vary the length of in situ acclimation periods for reintroduced oryx, and expect a longer acclimation period to lead to shorter dispersal distances.

In this study, we demonstrate the utility of GPS/satellite telemetry for monitoring a reintroduced population, specifically for evaluating the effects of captive management and release timing on dispersal and establishment. In 2016, 21 oryx (19 of which carried GPS/satellite collars) were reintroduced into the OROAWR during the wet season. In 2017, 14 additional oryx (all collared) were released during the dry season. Prior to transportation to the release site, each group was managed under different conditions (see section Materials and Methods). We also experimentally evaluated the effect of acclimation period length. We use the movement behavior of reintroduced oryx during the first year after release to evaluate the impact of intrinsic (such as sex and age) and extrinsic (such as management background and release timing, acclimation period, and local environmental conditions) factors on dispersal and establishment. Assessing our expectations with empirical movement data will inform future management of the oryx reintroduction effort. In addition, experiences reintroducing oryx in Chad can provide valuable lessons for reintroducing ungulates in general, as well as other reintroductions in highly variable environments.

\section{MATERIALS AND METHODS}

\section{Study Site}

Gazetted in 1969, the OROAWR is a large protected area in central Chad that contains $93,687 \mathrm{~km}^{2}$ of desert and subdesert ecosystems. Local habitats are typical of Sahelian and sub-Saharan regions and include wooded grasslands, sub-desert grasslands, and desert. Most of the reserve consists of relatively featureless, low terrain ranging from 190 to $461 \mathrm{~m}$ in elevation, occasionally crossed by wadis (seasonal streams) and rock outcroppings. While hunting is prohibited within the reserve, nomadic pastoralists make extensive use of native vegetation for livestock grazing. Both the Critically Endangered dama gazelle (Nanger dama) and Vulnerable Dorcas gazelle (Gazella dorcas) occur within the reserve (Newby et al., 2008; IUCN 
SSC Antelope Specialist Group, 2017). In addition, temporary wetlands within the OROAWR-primarily the Ouadi Kharma and Ouadi Achim - support migrating and overwintering white storks, ducks, waders, and passerines (Newby et al., 2016). Other native species such as the addax (Addax nasomaculatus), cheetah (Acinonyx jubatus), and African wild dog (Lycaon pictus) are locally extinct.

The OROAWR experiences the extreme seasonal cycles characteristic of arid Sahelian environments. From March to June, the region is hot and dry, and temperatures may soar to nearly $50^{\circ} \mathrm{C}$. During the rainy season-approximately July to September-rainfall occurs in a decreasing gradient from South to North, with ca. $400 \mathrm{~mm}$ total annual precipitation near the Southeast boundary of the Reserve, and $20 \mathrm{~mm}$ near the Northern boundary. From November to February, the region is relatively cool, with vegetation senescence and dormancy varying from December to February. In addition to this temporal variation, precipitation events are highly localized, leading to strong spatial variation in vegetation greenup, productivity, and nutritional quality.

\section{Study Species}

Scimitar-horned oryx are highly distinctive antelope. Both sexes are predominantly white in color, accented by a rufous mask across their forehead, neck, and shoulders, with long, curved, corrugated horns arching over their back. Horns may grow to $90-115 \mathrm{~cm}$ long in adults, with minimal sexual dimorphism (Dixon et al., 1991; Morrow et al., 2013). The species' range once spanned North Africa, particularly the seasonal grasslands characteristic of sub-desert, Sahelian ecosystems (Newby, 1988; Iyengar et al., 2007). Preferred habitat types include rolling dunes, scrub vegetation, and scattered trees or woodlands that provide shade during the dry season (Bassett, 1975; Newby, 1978, 1988; Bemadjim et al., 2012). Oryx feed on a wide variety of grasses and forbs and rarely drink surface water, instead obtaining moisture from grazed vegetation, wild Citrullus melons, and occasionally Acacia seed pods (Gillet, 1965; Dragesco-Joffé, 1993.

Historically, oryx were relatively abundant within their range, and were hunted for meat and hides (Dolan, 1966; Newby, 1980, 1988). Increased hunting pressure, arising from political instability and the introduction of automated weapons and motorized vehicles, along with exclusion from high-quality habitat by nomadic pastoralists and insufficient legal protection, resulted in the species' steady decline during the twentieth century (Durant et al., 2014; Woodfine and Gilbert, 2016). The last sightings of oryx in the wild occurred in the late 1980s (Newby, 1988), and the species was officially classified as Extinct in the Wild in 1999 (Hilton-Taylor, 2000).

Beginning in the mid-2000s, the Environment Agency-Abu Dhabi (EAD) and the Sahara Conservation Fund held a series of stakeholder workshops, ultimately securing strong support among international experts, government officials, and local leaders for the reintroduction of oryx to Chad. In 2012, a matrix evaluation approach including biological, social, political, and economic factors identified the OROAWR as the most favorable potential release site in Chad. Subsequent wildlife surveys, field visits, and remote sensing analyses (Freemantle et al., 2013) supported the selection of the OROAWR, and identified a specific release location-based historical data, the presence of shade trees, and the availability of preferred food plants. Infrastructure at the release site includes two $500 \mathrm{~m} \times 500 \mathrm{~m}$ pens, a smaller holding pen, shade structures, restraint devices and chutes for animal handling operations, and a permanent camp for project staff.

The source population for this reintroduction is the "World Herd" in Abu Dhabi managed by EAD. This large, genetically diverse population was drawn from extensive in-country collections and other captive populations around the world. In March 2016, 25 oryx were transported to the OROAWR and allowed to acclimate to local climate and forage conditions for 6 months. This cohort was raised under semi-free roaming conditions, i.e., in large enclosures (ca. 100 ha) with free access to natural vegetation; we thus refer to them as "ranging" oryx. In August 2016, 21 ranging oryx were released near the beginning of the wet season. In December 2016, additional oryx were transported to the OROAWR and acclimated to local conditions for 1 month. These animals were raised in smaller pens (ca. $50 \times 70 \mathrm{~m}$ ), provided with food and water via troughs, and had negligible access to natural vegetation; we thus refer to them as "penned" oryx. In January 2017, 14 penned oryx were released near the beginning of the dry season. In sum, several extrinsic factors were experimentally manipulated between release cohorts: (1) management background (access to natural foraging) and release timing (released in wet vs. dry season), and (2) acclimation period (1-6 months). The total reintroduced population during the study period comprised 14 males ( 5 sub-adults, 4 young adults, and 5 adults) and 16 females ( 6 sub-adults, 7 young adults, and 3 adults). A summary of the survival and fecundity of penned and ranging oryx during the study period is shown in Appendix A (Supplementary Material).

\section{Monitoring Protocol and Data Collection}

Because the scimitar-horned oryx has been Extinct in the Wild for nearly two decades, relatively little is known of its ecology in a wild setting. Accordingly, conservation research and monitoring are central to the oryx reintroduction effort. All reintroduced animals are intensively monitored by both tracking devices (unless deemed inappropriate for animal health or welfare concerns) and a field monitoring team. Stabach et al. (in review) showed that GPS/satellite collars weighing $<1 \%$ of an oryx's body weight had minimal impacts on oryx behavior or fecal stress hormone levels.

We briefly restrained ( $<10 \mathrm{~min}$ ) oryx in a drop-chute restraint device (Fauna TAMER Jr., Fauna Research Inc., Red Hook, NY, USA). While animals were restrained, we assessed body condition and general health, and attached GPS collars (VECTRONIC Aerospace $\mathrm{GmbH}$, Berlin, Germany). In total, we attached collars to 33 reintroduced oryx (19 ranging and 14 penned). Of these collars, 25 collected GPS locations every hour, three recorded positions every $2 \mathrm{~h}$, and two collected GPS locations every $4 \mathrm{~h}$. Four collars malfunctioned during the study period; all other individuals were monitored for at least 1 year (52 weeks) after release. The resulting set of data for 16 ranging and 9 penned oryx for the first 52 weeks after their release represents the only 
record of free-roaming movements ever collected for scimitarhorned oryx.

\section{Data Analysis}

\section{Post-release Dispersal}

To evaluate the impact of intrinsic (such as sex and age) and extrinsic (such as captive management and release timing, acclimation period, and local environmental conditions) factors on oryx dispersal, we calculated median net displacement (the straight-line distance between the release site and an animal's current location) each week after release. We estimated local environmental conditions using NDVI calculated based on the 250-m MODIS pixel nearest in space and time to each GPS location. NDVI has been associated with the quantity, density, and nutritional value of photosynthetically active vegetation in non-forest systems, and is often a useful predictor of herbivore distribution (Bro-Jørgensen et al., 2008; Pettorelli et al., 2011; Borowik et al., 2013; Stabach et al., 2017). We calculated NDVI from 8-day composites of MODIS surface reflectance at 250$\mathrm{m}$ native resolution across the study period (Vermote, 2015) in Google Earth Engine (Gorelick et al., 2017).

We built generalized additive mixed models (GAMMs) with predictor variables expressed as parametric or smoothed terms, and competed all possible models using standard model selection criteria (pseudo- $R^{2}, \mathrm{AIC}, \mathrm{BIC}$, and likelihood ratio tests) to determine which model structure and variable combinations best explained variation in oryx dispersal following release (see Table 2). All GAMs were implemented in the R package $m c g v$ (Wood, 2011). The final model included the categorical predictor variables (1) management background (ranging or penned; inseparable and thus considered jointly with release timing), (2) short-term seasonality (wet or dry), and the smoothed predictor variables, (3) experience (weeks since release), (4) long-term seasonality (week of year), and (5) local NDVI. Smoothed predictor variables were implemented using penalized regression splines, and fixed effects were allowed to vary with management background. We also included a random effect (random intercept) for the identity of individual oryx, and an autocorrelation structure (corAR1) to account for the time series nature of the response variable.

\section{Exploratory Movements and Home Range Establishment}

A variogram is both a means to visualize time-lag-dependent behaviors in movement data and estimate autocorrelation in a non-parametric framework. We fitted variograms and continuous-time movement models (CTMMs) to GPS locations from each reintroduced oryx using the $\mathrm{ctmm}$ package (Calabrese et al., 2016) in the statistical analysis program $\mathrm{R}$ ( $\mathrm{R}$ Core Team, 2016). This continuous-time stochastic movement framework has many advantages over other movement analysis methods, including properly accounting for the serial autocorrelation intrinsic to movement data, handling irregularities and gaps, and appropriately estimating confidence intervals (Fleming et al., 2014a, 2015). We considered five candidate movement models: bivariate normal (Van Winkle, 1975), Brownian motion (Horne et al., 2007; Pozdnyakov et al., 2014), Ornstein-Uhlenbeck (OU) motion (Uhlenbeck and Ornstein, 1930), integrated OU (IOU) motion (Johnson et al., 2008; Gurarie and Ovaskainen, 2011), and a hybrid IOU-OU model (Fleming et al., 2014a). We fit models for each individual using the ctmm.fit function and a maximum likelihood approach. We verified range residency by

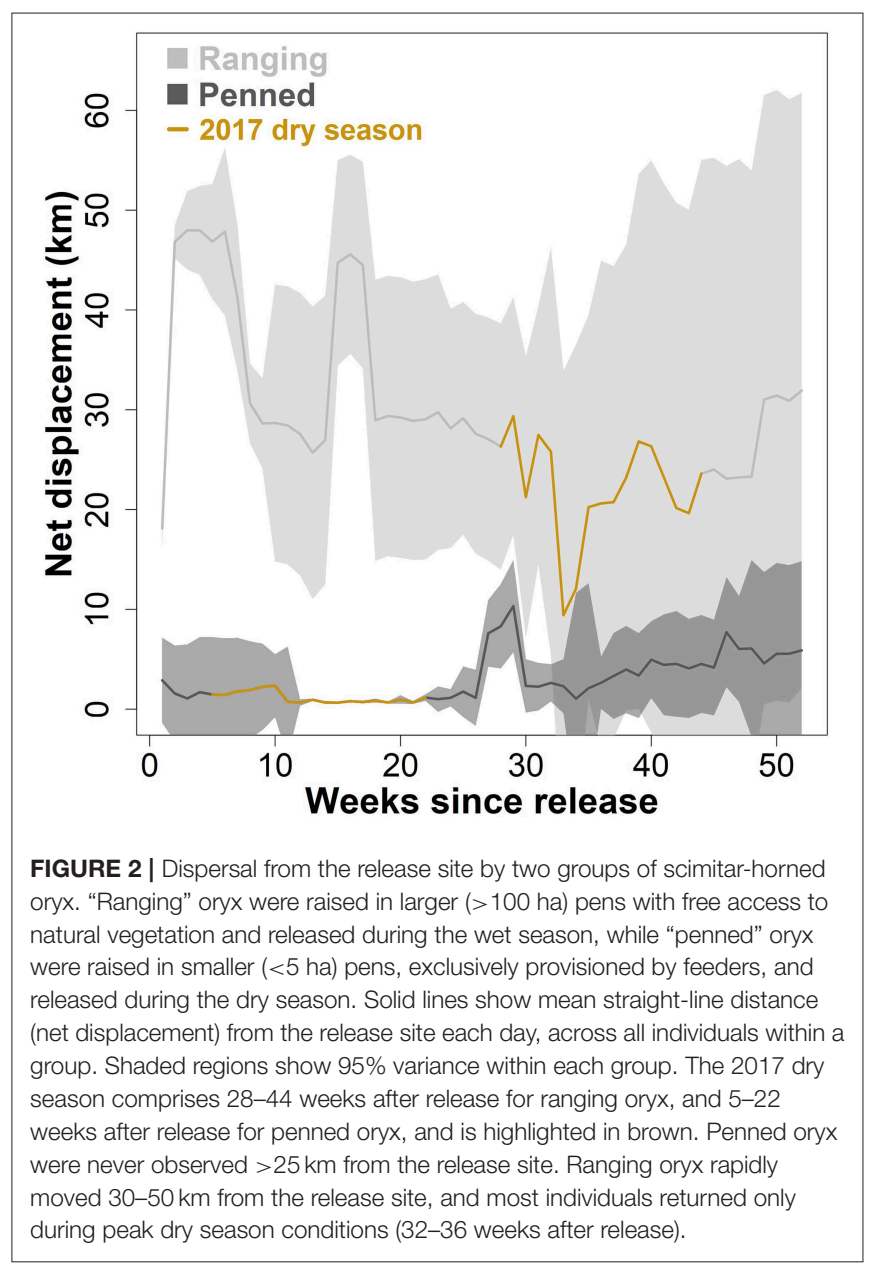

TABLE 1 | Post-release performance of scimitar-horned oryx.

\begin{tabular}{|c|c|c|c|c|c|c|}
\hline Management background & Release timing & No. animals released & Adult survival & Collar malfunctions & No. offspring & Calf survival \\
\hline Ranging & August 2016 (wet season) & 21 (19 collared) & $100 \%$ & $2(5 \%)$ & 4 & $50 \%$ \\
\hline Penned & January 2017 (dry season) & 14 (14 collared) & $100 \%$ & $1(7 \%)$ & 5 & $60 \%$ \\
\hline
\end{tabular}

Summary of animal and GPS collar performance during the study period (52 weeks after animals were released). 
visually examining the empirical semi-variogram to confirm that an asymptote was reached during the first half of the monitoring period (Calabrese et al., 2016). This resulted in the exclusion of two penned oryx from further analysis. To select a final model for each individual, we visually compared candidate models to $x-y$ scatter plots and empirical variograms, and used an informationtheoretic approach, selecting the ctmm model for each oryx with the lowest AICc.

Based on the post-release movements of other reintroduced large mammals (Ryckman et al., 2010; Yott et al., 2011; Scillitani et al., 2012; Schmitz et al., 2015; Bleisch et al., 2017; Sarmento et al., 2017), we expect reintroduced oryx to spend time exploring their new environment before exhibiting the more constrained movements associated with home range residency. To measure the duration of this initial exploratory period, we compared the home range estimated from an oryx's entire movement trajectory,

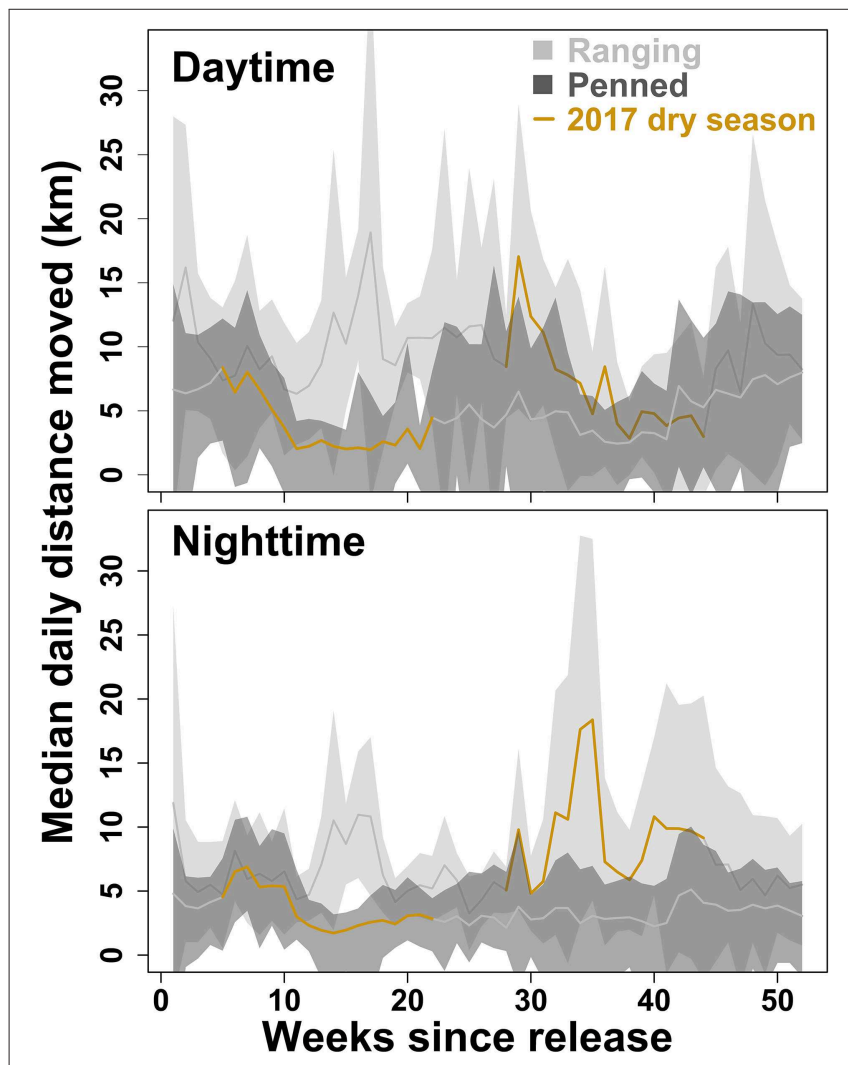

FIGURE 3 | Daily distance moved by two groups of scimitar-horned oryx. "Ranging" oryx were raised in larger (>100 ha) pens with free access to natural vegetation and released during the wet season, while "penned" oryx were raised in smaller ( $<5$ ha) pens, exclusively provisioned by feeders, and released during the dry season. Solid lines show median distance moved each day, during daytime (06:01-18:00) or nighttime (18:01-06:00) periods, across all individuals within a group. Shaded regions show 95\% variance within each group. The 2017 dry season comprises 28-44 weeks after release for ranging oryx, and 5-22 weeks after release for penned oryx, and is highlighted in brown. Ranging oryx generally traveled further each day $(6-10 \mathrm{~km})$ than penned oryx (3-7 km; Welch two-sample $t$-test, $p<0.001$ ). During the 2017 dry season, ranging oryx altered their movement behavior to move greater distances during cooler nighttime periods, while penned oryx simply moved less overall. to home ranges estimated from subsampled trajectories. More specifically, we generated 40 subsampled movement trajectories for each reintroduced oryx by excluding progressively longer periods (e.g., 1, 2, .., 39, 40 weeks) immediately after release. We then estimated home ranges for all 41 movement trajectories and performed pairwise comparisons between home range estimated for the entire movement trajectory and each subsampled trajectory. We used Autocorrelated Kernel Density Estimation (AKDE) methods, which capture the long-term, 95\% coverage region of the probability distribution of all possible locations, given observed movement properties (Fleming et al., 2015), to estimate home ranges.

To identify the transition between exploration and home range establishment for each oryx, we used the Bhattacharyya coefficient, a metric initially derived to measure similarity among probability distributions (Bhattacharyya, 1943). This metric is proportional to areal overlap among distributions, does not depend on ad hoc parameters (such as isopleths), displays consistency across large sample sizes, and incorporates a correction for small sample sizes (Winner et al., 2018). We calculated Bhattacharyya coefficients and recorded confidence intervals for all pairwise comparisons of $\mathrm{AKDE}$ home ranges for each individual. When the confidence interval of the Bhattacharya coefficient does not overlap 1, AKDE home range estimates may be considered significantly different (Winner et al., 2018). Thus, we use the time after release at which the Bhattacharya confidence interval for the entire and subsampled trajectory no longer overlaps 1 to determine when exploratory movements were satisfactorily excluded. For each group of reintroduced oryx, we estimated the group-level exploratory period as the time after release when this criterion was met for the majority of the group.

\section{Supplementary Resource Use}

Standard captive management practices do not expose animals to resource scarcity or loss of body condition. The first dry season after release thus presented a substantial potential risk to captive-born oryx released into the OROAWR. In response, supplemental food and water were provided at the release site starting in January 2017, and field reports suggested that at least some oryx visited them regularly. To investigate the extent to which reintroduced oryx used supplemental food and water, and accurately estimate visitation rates, we extrapolated locations of each oryx at a very fine temporal resolution ( $5 \mathrm{~min}$ ) using the predict function in the $\mathrm{ctmm}$ package. Introduced by Fleming et al. (2016), this approach employs time-series kriging to estimate unobserved locations based on the recorded movement trajectory, a fitted ctmm model, and an error process.

To assess the spatial accuracy of predicted locations, we thinned each 1 -h movement trajectory by $50 \%$, predicted the missing locations, and measured the distance between predicted and actual locations. On average, kriging with the best-fitting $\mathrm{ctmm}$ movement model for the entire trajectory produced point estimates that were $<110 \mathrm{~m}( \pm 80.3 \mathrm{~m})$ from actual locations. We detected no significant variation among prediction accuracy for individual oryx or release groups. This spatial error is acceptable, because it is largely contained within the 

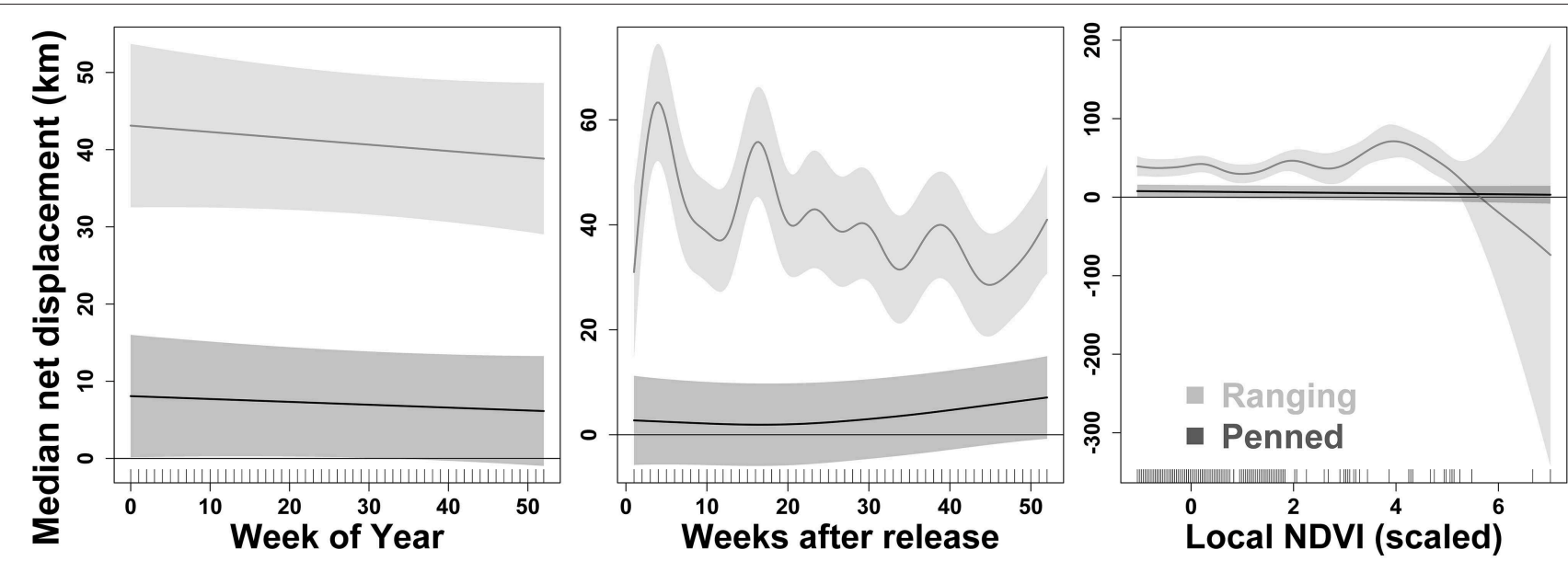

FIGURE 4 | Two groups of scimitar-horned oryx exhibit differential responses to post-release experience and local environmental conditions. Here, we show summed effects on dispersal from the release site estimated by generalized additive mixed models (GAMMs). Each predictor variable is a smoothed term fit using a penalized regression spline. "Ranging" oryx were raised in larger (>100 ha) pens with free access to natural vegetation and released during the wet season, while "penned" oryx were raised in smaller ( $<5$ ha) pens, exclusively provisioned by feeders, and released during the dry season. Ranging oryx disperse from the release site relatively quickly, followed by variation in dispersal distance over time apparently unrelated to seasonality (see "Week of Year," Left Panel). In contrast, penned oryx move further from the release site very gradually after release (see "Weeks after release," Center Panel). Ranging oryx also vary movements and dispersal in response to local environmental and forage conditions, while penned oryx appear largely unaffected by these factors [see "Local NDVI (scaled)," Right Panel]. In the Right Panel, ticks along the $\mathrm{x}$-axis show observed data points. The 2017 dry season comprises 28-44 weeks after release for ranging oryx, and 5-22 weeks after release for penned oryx. See Table 2 for coefficient estimates for all predictor variables in the final GAMM.

area where supplementary resources were provided (a roughly circular area 2.3 ha in size). Thus, we used predicted locations at $5 \mathrm{~min}$ temporal resolution to evaluate individual use of supplementary resources.

We counted intersections of the high-resolution, predicted trajectory with a polygon boundary delineating the area where supplemental resources were provided ( $100 \mathrm{~m}$ buffer). To avoid multiple counts of the same visit, we limited each oryx to one visit every $3 \mathrm{~h}$ (the approximate duration of an extended foraging bout; T. Wacher, personal communication). To account for size differences between the ranging and penned groups, we used mean daily visits per individual to capture group-level use of supplemental resources.

\section{RESULTS}

During the monitoring period, we collected more than 230,000 GPS locations for 33 reintroduced scimitar-horned oryx. Ranging oryx released during the wet season exhibited relatively similar survival and collar malfunction rates as penned oryx released during the dry season (Table 1). The median number of locations collected per collared individual was 7,200. The best and most common continuous-time movement model selected for reintroduced oryx was an Ornstein-Uhlenbeck motion model with foraging ("OUF"). The OUF model features autocorrelation in both position and velocity (meaning that an animal's location, direction, and speed are correlated through time), as well as restricted space use (Fleming et al., 2014a,b). Selection of this model indicates (1) a well-defined home range, and (2) the existence of relatively small, linear movements over short time scales characteristic of ungulate foraging, as described in Fleming et al. (2014b).

Overall, ranging oryx released during the wet season both dispersed further from the release site (Figure 2), and moved across their novel environment more (Figure 3), than penned oryx released during the dry season. During the study period, most ranging oryx moved at least $50-70 \mathrm{~km}$ from the release site, with one individual traveling more than $120 \mathrm{~km}$ away. In contrast, penned oryx traveled a maximum of $25 \mathrm{~km}$ from the release site, with most movements within $15 \mathrm{~km}$ (Figure 2). Ranging oryx moved significantly further $(6-10 \mathrm{~km})$ each day than penned oryx $(3-7 \mathrm{~km}$, Welch two-sample $t$ test, $t=9.136, d f=16.936, p<0.001)$. Ranging oryx also exhibited greater within-group variation in net displacement (Welch two-sample $t$-test, $t=6.8239, d f=164.44, p<$ 0.001). During the 2017 dry season, ranging oryx responded to the extreme hot, dry conditions by altering their movement behavior to travel primarily at night, and exhibited greater inter-individual variation in daily distance moved (Figure 3). By comparison, penned oryx simply moved shorter distances overall (Figure 2).

Morrow et al. (1999) found that captive oryx in North America produced calves approximately every 8-11 months, with a median inter-birth interval of 277 days. Calf survival rates in captivity are highly variable, with $19-35 \%$ of calves surviving to 6 months of age (Morrow et al., 1999; Gilbert, 2010; Little et al., 2016). Compared to these potential calving rates, relatively low proportions of ranging (30\%) and penned (50\%) females produced offspring during the study period. However, roughly equivalent proportions of calves in the reintroduced population survived to adulthood (50-60\%). 


\section{Post-release Dispersal}

GAMMs revealed strong influences of extrinsic, but not intrinsic, factors on the dispersal of reintroduced oryx (Figure 4). The joint effect of management background and release timing explained by far the largest proportion of variance in oryx dispersal (48\%). While the influence of sex and age were statistically significant $(p<0.0001)$, neither variable explained more than $10 \%$ of variance in the data or meaningfully lowered AIC or BIC values. In contrast, the extrinsic factors of short-term seasonality (categorical variable for "wet" or "dry" season), experience (weeks

TABLE 2 | Intrinsic and extrinsic factors affect the dispersal of reintroduced scimitar-horned oryx.

\begin{tabular}{|c|c|c|c|c|c|c|}
\hline $\begin{array}{l}\text { (A) Predictor } \\
\text { variables }\end{array}$ & Type & \multicolumn{3}{|c|}{ Description } & \multicolumn{2}{|l|}{ Values } \\
\hline $\begin{array}{l}\text { Management } \\
\text { background (grp) }\end{array}$ & Categorical & \multicolumn{3}{|c|}{$\begin{array}{l}\text { Management conditions } \\
\text { prior to reintroduction }\end{array}$} & \multicolumn{2}{|c|}{ Ranging, penned } \\
\hline Sex & Categorical & \multicolumn{3}{|c|}{ Individual's sex } & \multicolumn{2}{|c|}{ Male, female } \\
\hline Season & Categorical & \multicolumn{3}{|c|}{ Short-term seasonality } & \multicolumn{2}{|l|}{$\begin{array}{l}\text { Wet, } \\
\text { dry }\end{array}$} \\
\hline Age (agemo) & Continuous & \multicolumn{3}{|c|}{$\begin{array}{l}\text { Age in months at time of } \\
\text { release (scaled) }\end{array}$} & \multicolumn{2}{|c|}{$\begin{array}{l}22-61 \\
(-0.9,2.7)\end{array}$} \\
\hline $\begin{array}{l}\text { Individual identity } \\
\text { (indiv_ID) }\end{array}$ & Categorical & \multicolumn{3}{|c|}{$\begin{array}{l}\text { Measurements collected } \\
\text { from same individual are } \\
\text { autocorrelated }\end{array}$} & \multicolumn{2}{|c|}{ Individual identity } \\
\hline Week of year (wsr) & Continuous & \multicolumn{3}{|c|}{$\begin{array}{l}\text { Long-term seasonality } \\
\text { (scaled) }\end{array}$} & \multicolumn{2}{|c|}{$\begin{array}{l}1-52 \\
(-1.7,1.7)\end{array}$} \\
\hline $\begin{array}{l}\text { Weeks since release } \\
\text { (woy) }\end{array}$ & Continuous & \multicolumn{3}{|c|}{$\begin{array}{l}\text { Experience traversing novel } \\
\text { landscape (scaled) }\end{array}$} & \multicolumn{2}{|c|}{$\begin{array}{l}1-52 \\
(-1.7,1.7)\end{array}$} \\
\hline Local NDVI (ndvi) & Continuous & \multicolumn{3}{|c|}{$\begin{array}{l}\text { Vegetation greenness index } \\
\text { calculated from MODIS } \\
\text { data (scaled) }\end{array}$} & \multicolumn{2}{|l|}{$\begin{array}{l}0-1 \\
(-1,7)\end{array}$} \\
\hline \multicolumn{2}{|c|}{ (B) Single-variable models } & & $R^{2}$ & AIC & BIC & $\operatorname{Pr}(>|t|)$ \\
\hline grp & & & 0.4820 & 11,835 & 11,851 & NA \\
\hline sex & & & 0.0103 & 12,785 & 12,801 & $<0.0001$ \\
\hline season & & & 0.0215 & 12,767 & 12,785 & $<0.0001$ \\
\hline agemo & & & 0.0987 & 12,648 & 12,664 & $<0.0001$ \\
\hline woy & & & 0.0161 & 12,777 & 12,793 & $<0.0001$ \\
\hline s(woy) & & & 0.0578 & 12,721 & 12,776 & $<0.0001$ \\
\hline wsr & & & 0.0202 & 12,771 & 12,787 & $<0.0001$ \\
\hline$s(w s r)$ & & & 0.0368 & 12,753 & 12,809 & $<0.0001$ \\
\hline ndvi & & & 0.0031 & 12,796 & 12,812 & 0.02 \\
\hline$s(n d v i)$ & & & 0.0727 & 12,752 & 12,697 & $<0.0001$ \\
\hline (C) Final model & & & $R^{2}$ & AIC & BIC & $\operatorname{Pr}(>|t|)$ \\
\hline grp + season $+s($ & oy) + & i) & 0.8510 & 10,069 & 10,415 & NA \\
\hline
\end{tabular}

We constructed GAMMs to evaluate how intrinsic (sex, age, and other individual characteristics) and extrinsic (management background, local environmental conditions, seasonality, and experience) factors affect the dispersal of reintroduced oryx. We built initial models with single, independent predictors $(A)$ and then used standard model selection criteria (pseudo- $R^{2}, A I C, B I C$, and likelihood ratio tests; see (B) to determine which combinations of variables best explained variation in oryx dispersal. The final model (C) included the best-performing and most parsimonious combination of parametric and smoothed predictor variables, as well as a random effect (random intercept) for individual oryx, and an autocorrelation structure to account for the time series nature of the response variable (corAR1). since release), long-term seasonality (week of year), and local forage conditions (MODIS NDVI) jointly explained another $30-35 \%$ of variance in oryx dispersal (see Table 2). Summed response curves showing the effects of individual predictor variables (while holding the effects of other variables to mean values) indicate that ranging oryx responded to favorable local forage conditions (i.e., relatively high NDVI values) by moving away from the release site (Table 3 ). The dramatic increase in variance of net displacement at the highest NDVI values recorded indicates that ranging oryx implement individualistic strategies under favorable conditions. Adding individual identity as a random effect substantially increased the amount of variance explained by the final model and decreased AIC and BIC (Table 2)-potentially capturing some of the variance explained by parametric predictor variables sex and age, but indicating the persistent importance of individual-level variation.

\section{Exploratory Movements and Home Range Establishment}

Excluding initial exploratory movements dramatically improved $\mathrm{ctmm}$ model fit for all individuals, reducing the variance around empirical semivariograms by $50-100 \%$ (Figure 5). Ranging oryx showed the expected pattern of wide-ranging exploratory movements immediately after release, followed by home range establishment. The transition from exploration to residency predominantly occurred by 27 weeks $( \pm 3.9$ weeks) after release (Figure 6). During the exploratory period, ranging oryx traversed a high proportion of novel territory, yielding AKDE home range estimates that decreased in area until reaching a rough asymptote corresponding to the home range. Mean home range size for ranging oryx was $1,078 \mathrm{~km}^{2}\left( \pm 113 \mathrm{~km}^{2}\right)$. After establishment, ranging oryx crossed their home range roughly every 45 days ( \pm 23 days).

In general, penned oryx did not engage in exploratory movements after release, instead visiting lower proportions of

TABLE 3 | Estimated effects of intrinsic and extrinsic factors on the dispersal of reintroduced scimitar-horned oryx.

\begin{tabular}{lcccc}
\hline (A) Parametric coefficients & Estimate & Std. Error & $\boldsymbol{t}$-value & $\boldsymbol{p}$-value \\
\hline (Intercept) & 29.7070 & 2.5036 & 12.9340 & $<0.0001$ \\
Penned management & -27.1516 & 4.2851 & -7.9088 & $<0.0001$ \\
Wet season & 2.5312 & 1.370 & 1.8460 & 0.0648 \\
\hline (B) Smoothed terms & edf & Ref. df & F-value & p-value \\
\hline s(week of year):ranging & 1.0000 & 1.0000 & 1.3810 & 0.2397 \\
s(week of year):penned & 1.0000 & 1.0000 & 0.7462 & 0.0290 \\
s(weeks after release):ranging & 16.1843 & 16.8690 & 29.6860 & $<0.0001$ \\
s(weeks after release):penned & 2.0276 & 2.5166 & 8.1295 & 0.0210 \\
s(local NDVI):ranging & 10.5339 & 11.9404 & 11.4396 & $<0.0001$ \\
s(local NDVI):penned & 1.0000 & 1.0000 & 2.4114 & 0.1205 \\
\hline
\end{tabular}

Estimated coefficients and significance for all fixed effects in the final GAMM for median weekly net displacement, for both parametric coefficients and smoothed terms (fit using penalized regression splines). 


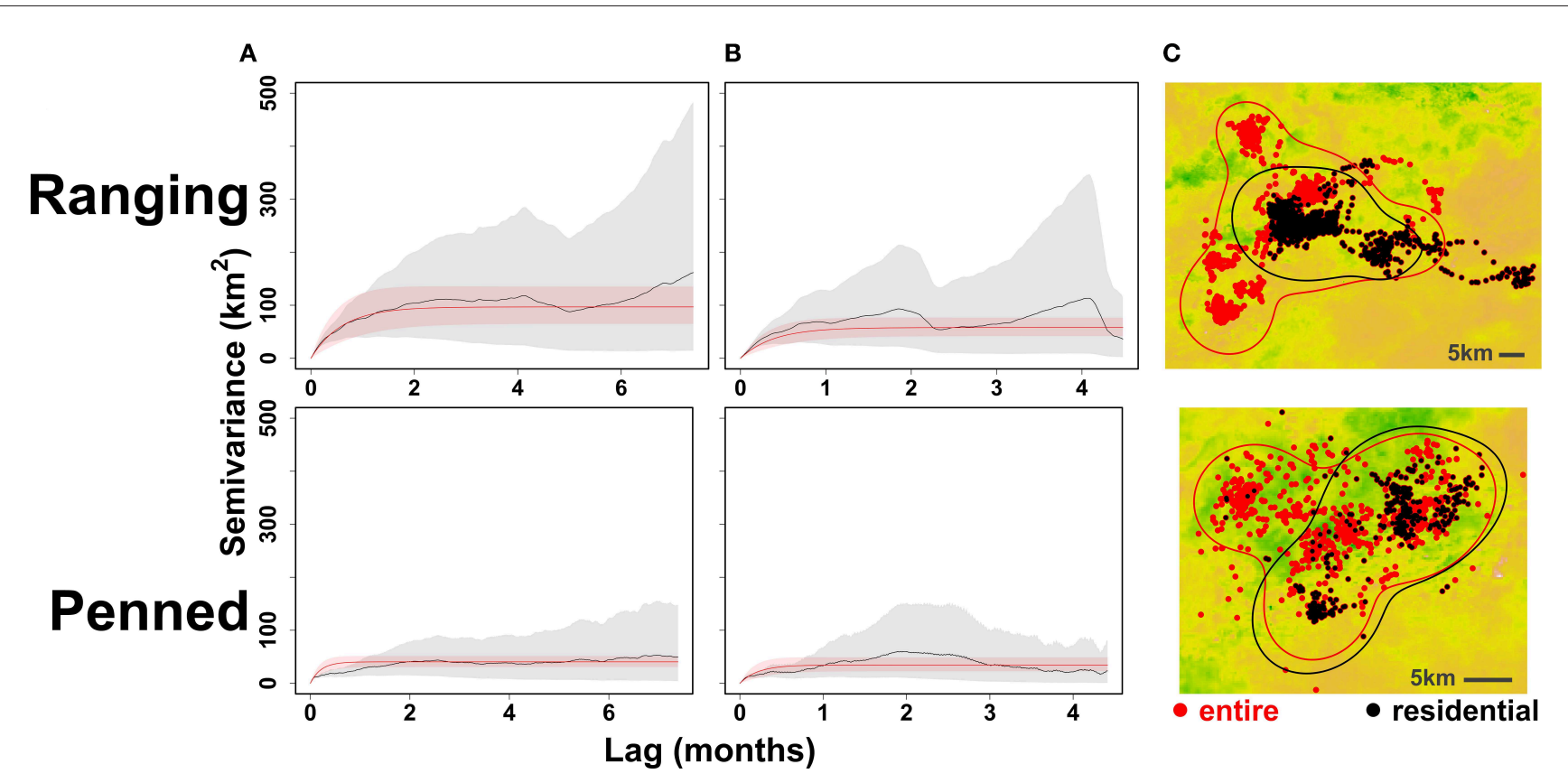

FIGURE 5 | Impact of excluding exploratory movements from home range estimation. "Ranging" oryx were raised in larger ( $>100$ ha) pens with free access to natural vegetation and released during the wet season, while "penned" oryx were raised in smaller $(<5 \mathrm{ha})$ pens, exclusively provisioned by feeders, and released during the dry season. For an example individual from each release group (ranging: female 23_BLU, penned: male 21_BLU), we identified and removed exploratory movements performed immediately after release. Empirical (gray) and model (red) semivariograms are shown for the entire movement trajectory (A) and for residential movements only (B). When only residential movements are considered, both variation in semivariance and 95\% AKDE home range estimates substantially decrease (C).

new territory and yielding AKDE home range estimates similar in area and location until up to 40 weeks after release. The time to home range establishment was much more variable, ranging from 5 to 40 weeks after release, with an average transition time of 35 weeks ( \pm 4.9 weeks). Penned oryx also established much smaller home ranges of $472 \mathrm{~km}^{2}\left( \pm 247 \mathrm{~km}^{2}\right)$, and crossed their home ranges approximately every 11 days ( \pm 5 days).

\section{Supplementary Resource Use}

Penned oryx used supplementary resources significantly more than ranging oryx (Figure 7). Indeed, ranging oryx released during the wet season largely did not return to the release site until 32-34 weeks after release, during peak conditions of the dry season (Figure 7). By comparison, penned oryx released during the dry season used supplementary food and water continuously, from immediately after release through the end of the study period (all pairwise comparisons across management background and season $p<0.01$, Kruskal-Wallis test and Dunn's post-hoc test). While all oryx accessed supplementary food and water less during the wet season (Tukey's HSD, all $p<0.001$ ), penned oryx used supplementary resources significantly more during the wet season than ranging oryx did during the dry season (Tukey's HSD, $p<0.0001$ ). These results align with anecdotal evidence from field monitoring personnel that penned oryx consumed supplementary food and water on an almost daily basis.

\section{DISCUSSION}

The GPS tracking of scimitar-horned oryx reintroduced to the OROAWR provided new insights into the basic biology of oryx, as well as critical information about factors influencing the rate and extent to which naïve individuals adjust to a novel landscape. Experimental manipulation of management strategies revealed the approaches most likely to influence long-term success of reintroduced individuals, and enabled the timely refinement of management actions. We demonstrated how research and monitoring can be integrated into a large conservation program to simultaneously test hypotheses, improve short- and longterm conservation outcomes, and gain crucial knowledge for future reintroductions.

We found significant differences in the capacity of naïve individuals and release cohorts to adapt to the seasonal variation typical of desert environments, resulting in two distinct movement strategies. We monitored two groups of oryx released into the OROAWR, which differed in joint management and release timing treatments ("ranging" oryx released during the wet season vs. "penned" oryx released during the dry season), as well as acclimation period. Based on previously reported post-release movements of other large mammals, we expected reintroduced oryx to explore their novel environment immediately after release and then establish individual home ranges. A hybrid integrated Ornstein-Uhlenbeck motion (“OUF") movement model best fit the movement trajectories of both ranging and penned oryx, suggesting that oryx from different management backgrounds 


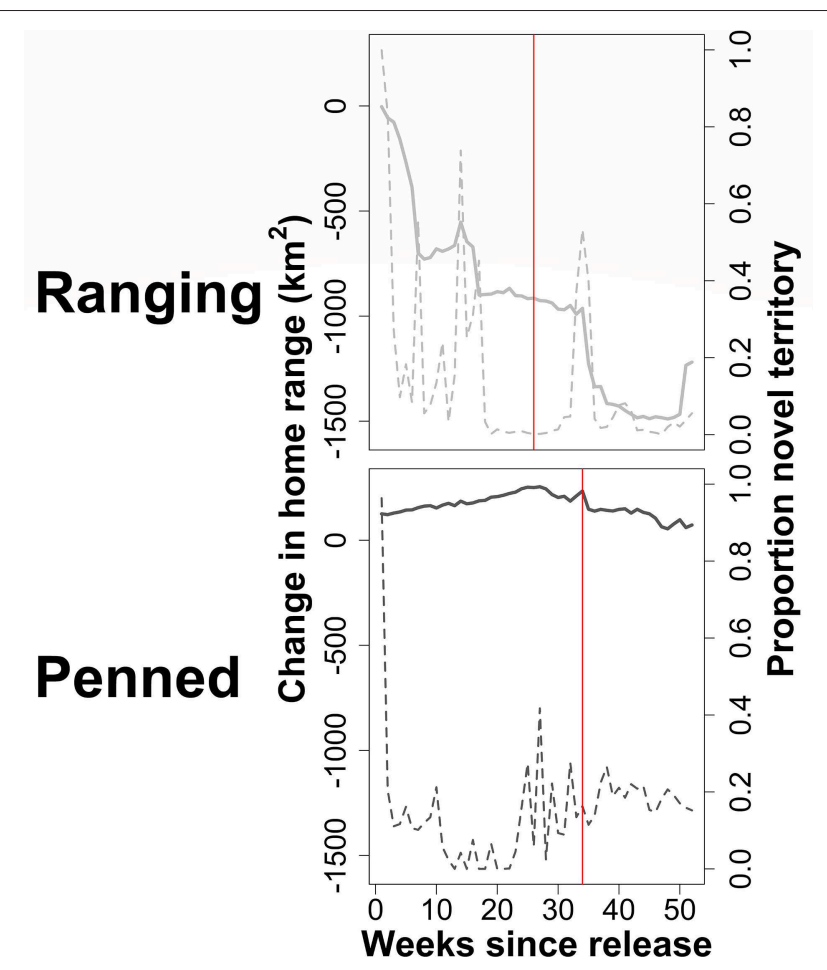

FIGURE 6 | Exploration of a novel environment by two groups of scimitar-horned oryx. "Ranging" oryx were raised in larger (>100 ha) pens with free access to natural vegetation and released during the wet season, while "penned" oryx were raised in smaller ( $<5$ ha) pens, exclusively provisioned by feeders, and released during the dry season. Solid gray lines show change $\left(\mathrm{km}^{2}\right)$ in AKDE home range estimates as consecutive weeks of movements are excluded from analysis. Dashed gray lines show the proportion of novel (previously unexplored) territory included in an estimated home range. Solid red lines indicate the time after release at which home ranges for each group are exclusively residential, i.e., all exploratory movements are excluded. Ranging oryx exhibited the expected pattern of wide-ranging exploratory movements immediately after release, including frequent excursions into novel territory, followed by adoption of a stable home range and home range residency. Penned oryx remained within a relatively small area after release, such that estimated home ranges were very similar, and visits to novel territory were infrequent.

and release seasons share basic movement properties. The OUF model specifically accommodates linear movements at short time scales-a characteristic feature of ungulate foraging movements (Fleming et al., 2014b) - and an eventual asymptote indicating home range establishment. However, after 1 year of monitoring, ranging oryx had dispersed $>40 \mathrm{~km}$ from the release site and established relatively large home ranges, while penned oryx had not meaningfully dispersed from the release site, and established smaller home ranges substantially later (or not at all).

The observed difference in home range size is the result of penned oryx simply moving less after release, over both short and long time scales. The underlying mechanism appears to lie in the different movement behaviors exhibited by each release cohortspecifically, their differential responses to local environmental conditions. Estimated sizes of AKDE home ranges and rangecrossing times were much smaller for penned oryx than ranging oryx. Ranging oryx also traversed much greater proportions of novel territory during successive weeks after release than penned oryx. In addition, as conditions grew more extreme during the 2017 dry season, ranging oryx moved primarily during the night and exhibited increased inter-individual variation in net displacement, while penned oryx simply (and universally) moved shorter distances overall.

In addition to their generally greater mobility, ranging oryx demonstrated the capacity to respond to spatial variation in environmental conditions. When exposed to favorable environmental conditions (i.e., when near high-quality forage, as indicated by high MODIS NDVI values near oryx GPS locations), ranging oryx dispersed farther from the release site, maintaining access to these high-quality resources. In contrast, penned oryx showed no measurable change in net displacement in response to nearby environmental conditions. Notably, postrelease experience (measured as weeks since release) was the only predictor that positively influenced dispersal by penned oryx. Thus, even during the portion of the study period when penned oryx were found at greater distances from the release site, their movements were not motivated by local conditions, but simply by the increasing amount of time spent as free-roaming individuals.

Notably, these outcomes are counter to the conventional wisdom regarding release techniques (Yott et al., 2011; Attum et al., 2013; Bleisch et al., 2017). Ranging oryx held for several months exhibited low site fidelity, while penned oryx held only briefly exhibited high site fidelity. While we cannot fully disentangle the impacts of management background, release timing, and acclimation period in this study, our findings suggest that, for scimitar-horned oryx, acclimation period may be the least influential of these factors.

Our study also reveals the potentially detrimental effect of supplemental feeding on naïve individuals reintroduced to a highly variable ecosystem. The extreme conditions of the 2017 dry season posed a concrete risk to released oryx, which were naïve to any kind of resource scarcity. Thus, supplemental food and water were provided at the release site starting in January 2017, located near the pre-release pens. The presence of accessible, unlimited food and water immediately after release may have provided a powerful attractant for penned oryx released during the dry season, and disconnected their movement decisions from local environmental conditions. Certainly penned oryx relied heavily on supplemental resources throughout the study period-even during the 2017 wet season, when natural forage was readily available. This finding adds to the ongoing debate over if, when, and how to provide supplemental resources in conservation programs (Ewen et al., 2015; Tollington et al., 2015).

The fundamental goal of a reintroduction program is to establish a viable population in the wild. Thus, many reintroduction managers seek to deter potentially risky behaviors, such as exploration of unfamiliar territory or long-distance dispersal, in favor of maximizing initial survival and population growth. However, in the highly temporally and spatially variable environment of the OROAWR, site fidelity may ultimately be a more precarious strategy than developing search techniques for high-quality resources, or gaining spatial memory, through exploratory movements. While spatial memory and learning enable animals to move through their landscape efficiently 


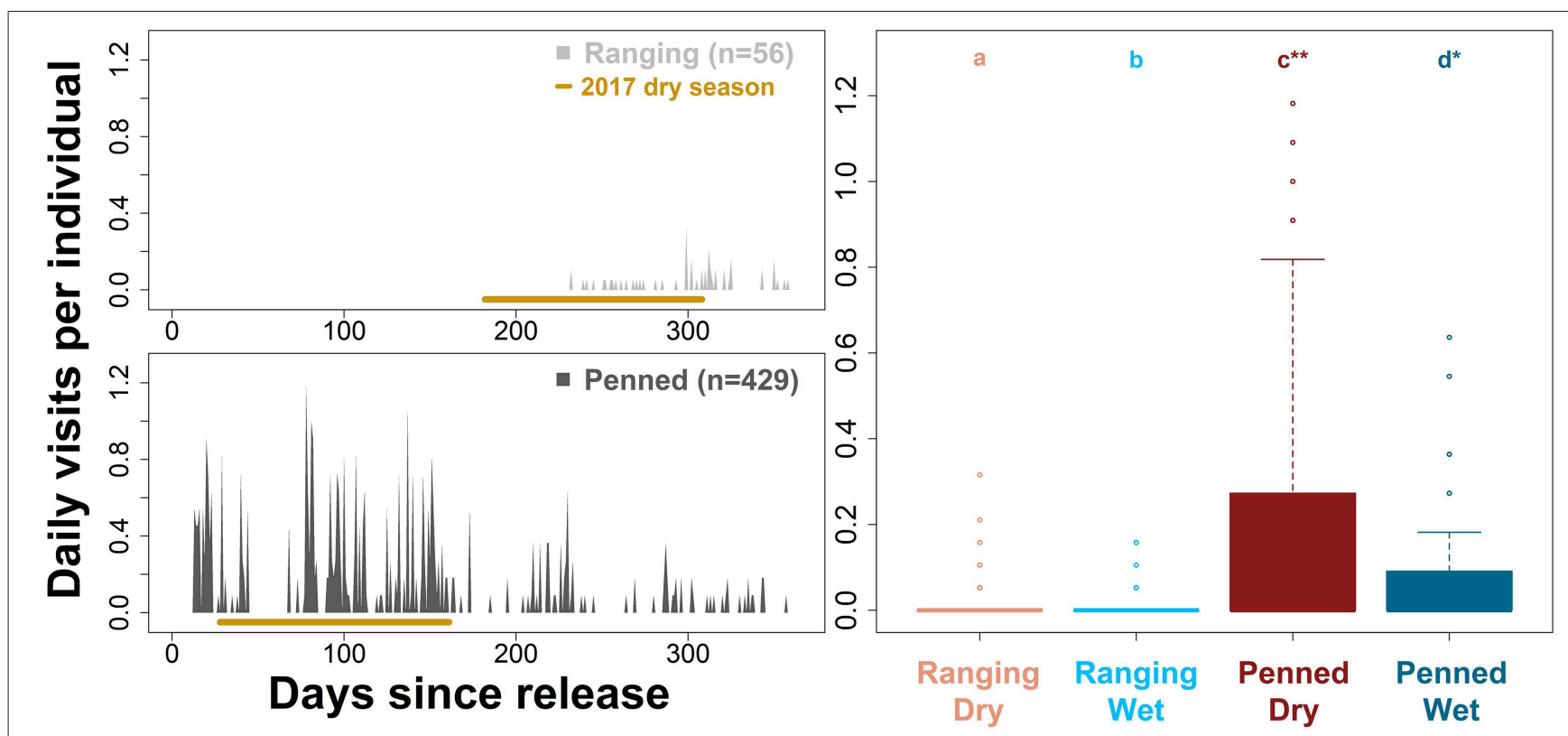

FIGURE 7 | Differential use of supplementary resources by two groups of scimitar-horned oryx. "Ranging" oryx were raised in larger (>100 ha) pens with free access to natural vegetation and released during the wet season, while "penned" oryx were raised in smaller ( $<5$ ha) pens, exclusively provisioned by feeders, and released during the dry season. We used predicted, high-resolution (5-min) trajectories to count the number of times oryx accessed supplementary food and water, limiting each individual to one visit every $3 \mathrm{~h}$. Bar graphs (Left) show mean daily visits per individual by each group. Ranging oryx used supplementary resources only during the 2017 dry season, while penned oryx used them regularly after release. The 2017 dry season comprises 28-44 weeks after release for ranging oryx, and 5-22 weeks after release for penned oryx, and is highlighted in brown. Box plots (Right) show variation in daily visits per individual by group and season. All season- and group-level comparisons were significantly different $\left(p<0.01\right.$ for a-d, according to Kruskal-Wallis test and Dunn's post-hoc test; ${ }^{\star} p<0.001$; * $\left.p<0.0001\right)$.

(Benhamou, 1994; Fagan et al., 2013, 2017), the process by which individuals acquire these skills is not well understood (Janson, 1998; Schlägel and Lewis, 2014; Bracis et al., 2015; Polansky et al., 2015). Certainly, individuals need time and exposure to a novel environment to acquire information and learn how to optimally exploit local habitat patches. Some evidence for relatively long exploratory periods can be found in other reintroductions. For example, released ibex spent 1-2 years before establishing home ranges comparable to resident animals (Scillitani et al., 2012) and reintroduced elk took 16 months to disperse and establish a stable distribution in eastern Ontario (Yott et al., 2011).

The movement and dispersal behaviors observed in reintroduced scimitar-horned oryx 1 year after release provide strong evidence for the value of (1) large reserves or enclosures, and (2) the opportunity to perform natural foraging behavior, in the management of captive ungulate populations. Only oryx previously managed under these conditions, and immediately exposed to favorable environmental conditions upon release, exhibited the expected pattern of exploratory movements across a novel landscape followed by establishment of a stable home range. Thus, we recommend that future releases of oryx in the current reintroduction project (and potentially other ungulate species) follow this model. In addition, while supplemental resources may prevent mortalities of naïve reintroduced animals due to extreme environmental conditions, this risk must be carefully balanced against the possibility that providing such resources may inhibit the development of natural responses to environmental conditions, and appropriate movement strategies in general. We recommend that supplemental resources be distributed based on observed need of individual animals, rather than ad libitum.

Remarkably, despite large differences in dispersal, home range size, and use of supplementary resources, ranging and penned oryx exhibited similar demographic outcomes. Unexpectedly low proportions of ranging (30\%) and penned (50\%) females produced offspring during the study period, with relatively low proportions of these calves surviving to adulthood (50-60\%). Many publications have quantified and emphasized the stress experienced by translocated or reintroduced wildlife (Teixeira et al., 2007; Aguilar-Cucurachi et al., 2010; Dickens et al., 2010; Bosson et al., 2013; Batson et al., 2017). Stress due to capture, handling, transport, disruption of social relationships, exposure to novel conditions, or other factors may certainly contribute to the unexpectedly low reproductive output observed in reintroduced oryx to date. We plan to continue monitoring all oryx in this study, as well as those in planned future releases and all offspring produced in the OROAWR, to assess the demographic effects of the intrinsic and extrinsic factors highlighted by this study, as well as the various movement strategies employed by reintroduced oryx.

\section{DATA AVAILABILITY STATEMENT}

The datasets for this study are not publicly available because the raw data supporting the analyses and conclusions presented in this article contain sensitive information; namely, the location of a very small population of a highly endangered species 
previously hunted for utilitarian and trophy purposes. In the effort to protect this population, the raw movement data are not publicly available. Requests to access these data should be directed to the Environment Agency of Abu Dhabi and the Sahara Conservation Fund.

\section{ETHICS STATEMENT}

The procedures implemented in this study were authorized under a cooperative agreement between the Sahara Conservation Fund (SCF) and the Ministre de l'Environnement, de l'Eau et de la Pêche. In accordance with this cooperative agreement, SCF guidelines, and local legislation in Chad, additional ethical approval was not required.

\section{AUTHOR CONTRIBUTIONS}

JN, JC, SA, and SM conceived and directed the broader reintroduction project. JN, JC, and TW implemented aspects of the project and supervised others. KM, JS, MS, and PL developed the analytical approach. KM conducted the analyses and wrote the manuscript with support from JS, MS, and PL. All authors discussed the results at various stages and contributed to the final manuscript.

\section{FUNDING}

Funding and support for the work described in this study was provided by His Highness Sheikh Mohammed bin Zayed Al Nahyan, Crown Prince of Abu Dhabi; the Chadian Ministère de l'Environnement, de l'Eau et de la Pêche; the Sahara Conservation Fund, the Disney Wildlife Conservation Fund, and the Association of Zoos and Aquariums.

\section{REFERENCES}

Aguilar-Cucurachi, M., Dias, P., Rangel-Negrín, A., Chavira, R., Boeck, L., and Canales-Espinosa, D. (2010). Preliminary evidence of accumulation of stress during translocation in mantled howlers. Am. J. Primatol. 72, 805-810. doi: 10.1002/ajp.20841

Armstrong, D. P., Castro, I., and Griffiths, R. (2007). Using adaptive management to determine requirements of re-introduced populations: the case of the New Zealand hihi. J Appl Ecol. 44, 953-962. doi: 10.1111/j.1365-2664.2007.01320.x

Armstrong, D. P., and Seddon, P. J. (2008). Directions in reintroduction biology. Trends Ecol. Evol. 23, 20-25. doi: 10.1016/j.tree.2007.10.003

Attum, O., Cutshall, C. D., Eberly, K., Day, H., and Tietjen, B. (2013). Is there really no place like home? Movement, site fidelity, and survival probability of translocated and resident turtles. Biodivers. Conserv. 22, 3185-3195. doi: 10.1007/s10531-013-0578-1

Bassett, T. (1975). Oryx and addax in chad. Oryx 13, 50-51. doi: $10.1017 /$ S0030605300013016

Batson, W. G., Gordon, I. J., Fletcher, D. B., Portas, T. J., and Manning, A. D. (2017). The effect of pre-release captivity on the stress physiology of a reintroduced population of wild eastern bettongs. J. Zool. 303, 311-319. doi: $10.1111 /$ jzo.12494

Beck, B. B., Rapaport, L. G., Stanley Price, M. R., and Wilson, A. C. (1994). "Reintroduction of captive-born animals", in Creative Conservation, eds P. J. S. Olney, G. M. Mace, and A. T. C. Feistner (Dordrecht: Springer), 265-286. doi: 10.1007/978-94-011-0721-1_13

\section{ACKNOWLEDGMENTS}

The Oryx Reintroduction Project in Chad is a joint initiative of the Government of Chad and the Environment Agency of Abu Dhabi. Under the overall leadership and management of the Environment Agency of Abu Dhabi, on-the-ground implementation of the project is carried out by the Sahara Conservation Fund. The Smithsonian Institution extends its gratitude to the Government of Chad, the Environment Agency of Abu Dhabi, and the Sahara Conservation Fund for the opportunity to assist in the project's implementation. We also thank the Environment Agency of Abu Dhabi for originating and managing the world herd of scimitar-horned oryx. We are grateful to the Ministre de l'Environnement, de l'Eau et de la Pêche for providing invaluable support to the Oryx Reintroduction Project in Chad. We also thank the Chef de Secteur Nord, Chef de Secteur Sud, Reserve Coordinateur Mahamat Hassan, and the entire ranger force of the OROAWR. We are grateful for the many hours of hard work by all SCF personnel working in the Ouadi Rimé-Ouadi Achim Wildlife Reserve, especially Marc Dethier, Krazidi Abeye, and Habib Ali. We also thank Ricardo Pusey, Maria Elena Pesci, Saeed Serhan Al Romaithi, Mohammed Manea Al Remeithi, Jon LLona Minguez, Louis Lignereux, Adam Eyres, Dan Beetem, Gavin Livingston, RoxAnna Breitigan, Julie Swenson, and the many others who have contributed time and expertise to the Oryx Reintroduction Project.

\section{SUPPLEMENTARY MATERIAL}

The Supplementary Material for this article can be found online at: https://www.frontiersin.org/articles/10.3389/fevo. 2019.00470/full\#supplementary-material

Bemadjim, N. E., Newby, J. E., Desbiez, A., Lees, C., and Miller, P. (2012). Technical Workshop on the Reintroduction of Scimitar-Horned Oryx to the Ouadi Rime-Ouadi Achim Game Reserve, Chad. IUCN/SSC Conservation Breeding Specialist Group.

Benhamou, S. (1994). Spatial memory and searching efficiency. Anim. Behav. 47, 1423-1433. doi: 10.1006/anbe.1994.1189

Beudels, R. C., Devillers, P., Lafontaine, R.-M., Devillers-Terschuren, J., and Beudels, M. O. (2005). Sahelo-Saharan Antelopes: Status and Perspectives. Bonn: CMS Technical Series Publication.

Bhattacharyya, A. (1943). On a measure of divergence between two statistical population defined by their population distributions. Bull. Calcutta Math. Soc. 35:28.

Bleisch, A. D., Keller, B. J., Bonnot, T. W., Hansen, L. P., and Millspaugh, J. J. (2017). Initial movements of reintroduced Elk in the Missouri Ozarks. Am. Midl. Nat. 178, 1-16. doi: 10.1674/0003-0031-178.1.1

Bonte, D., Van Dyck, H., Bullock, J. M., Coulon, A., Delgado, M., Gibbs, M., et al. (2012). Costs of dispersal. Biol. Rev. 87, 290-312. doi: 10.1111/j.1469-185X.2011.00201.x

Borowik, T., Pettorelli, N., Sönnichsen, L., and Jedrzejewska, B. (2013). Normalized difference vegetation index (NDVI) as a predictor of forage availability for ungulates in forest and field habitats. Eur. J. Wildl. Res. 59, 675-682. doi: 10.1007/s10344-013-0720-0

Bosson, C. O., Palme, R., and Boonstra, R. (2013). Assessing the impact of livecapture, confinement, and translocation on stress and fate in eastern gray squirrels. J. Mammal. 94, 1401-1411. doi: 10.1644/13-MAMM-A-046.1 
Bracis, C., Gurarie, E., Van Moorter, B., and Goodwin, R. A. (2015). Memory effects on movement behavior in animal foraging. PLOS ONE 10:e136057. doi: 10.1371 /journal.pone.0136057

Bro-Jørgensen, J., Brown, M. E., and Pettorelli, N. (2008). Using the satellitederived normalized difference vegetation index (NDVI) to explain ranging patterns in a lek-breeding antelope: the importance of scale. Oecologia 158, 177-182. doi: 10.1007/s00442-008-1121-z

Calabrese, J. M., Fleming, C. H., and Gurarie, E. (2016). ctmm: an r package for analyzing animal relocation data as a continuous-time stochastic process. Methods Ecol. Evolut. 7, 1124-1132. doi: 10.1111/2041-210X.12559

de la Luz Martinez-Garcia, J. (2009). Site Fidelity and Post Release Movements of Translocated Mule Deer in Northern Coahuila, Mexico. Alpine, TX: Sul Ross State University.

Dickens, M. J., Delehanty, D. J., and Romero, L. M. (2010). Stress: an inevitable component of animal translocation. Biol. Conserv. 143, 1329-1341. doi: 10.1016/j.biocon.2010.02.032

Dixon, A. M., Mace, G., Newby, J., and Olney, P. (1991). Management of captive populations of scimitar-horned oryx and addax for reintroduction. Symp. Zool. Soc. Lond. 62, 201-216.

Dolan, J. M. (1966). Notes on the scimitar-horned oryx, Oryx dammah (Cretzschmar, 1826). Int. Zoo Yearbook 6, 219-229. doi: 10.1111/j.1748-1090.1966.tb01772.x

Dragesco-Joffé, A. (1993). La vie sauvage au Sahara. Paris: Delachaux et Niestlé.

Durant, S. M., Wacher, T., Bashir, S., Woodroffe, R., De Ornellas, P., Ransom, C., et al. (2014). Fiddling in biodiversity hotspots while deserts burn? Collapse of the Sahara's megafauna. Divers. Distribut. 20, 114-122. doi: 10.1111/ddi. 12157

Ellis, D. H., Gee, G. F., Hereford, S. G., Olsen, G. H., Chisolm, T. D., Nicolich, J. M., et al. (2000). Post-release survival of hand-reared and parent-reared Mississippi Sandhill Cranes. Condor 102, 104-112. doi: 10.1093/condor/102.1.104

Ewen, J. G., Soorae, P. S., and Canessa, S. (2014). Reintroduction objectives, decisions and outcomes: global perspectives from the herpetofauna. Anim. Conserv. 17, 74-81. doi: 10.1111/acv.12146

Ewen, J. G., Walker, L., Canessa, S., and Groombridge, J. J. (2015). Improving supplementary feeding in species conservation. Conservat. Biol. 29, 341-349. doi: $10.1111 /$ cobi. 12410

Fagan, W. F., Gurarie, E., Bewick, S., Howard, A., Cantrell, R. S., and Cosner, C. (2017). Perceptual ranges, information gathering, and foraging success in dynamic landscapes. Am. Nat. 189, 474-489. doi: 10.1086/691099

Fagan, W. F., Lewis, M. A., Auger-Méthé, M., Avgar, T., Benhamou, S., Breed, G., et al. (2013). Spatial memory and animal movement. Ecol. Lett. 16, 1316-1329. doi: $10.1111 /$ ele. 12165

Fischer, J., and Lindenmayer, D. (2000). An assessment of the published results of animal relocations. Biol. Conserv. 96, 1-11. doi: 10.1016/S0006-3207(00)00048-3

Fleming, C. H., Calabrese, J. M., Mueller, T., Olson, K. A., Leimgruber, P., and Fagan, W. F. (2014a). Non-Markovian maximum likelihood estimation of autocorrelated movement processes. Methods Ecol. Evol. 5, 462-472. doi: 10.1111/2041-210X.12176

Fleming, C. H., Calabrese, J. M., Mueller, T., Olson, K. A., Leimgruber, P., and Fagan, W. F. (2014b). From fine-scale foraging to home ranges: a semivariance approach to identifying movement modes across spatiotemporal scales. Am. Nat. 183, E154-E167. doi: 10.1086/675504

Fleming, C. H., Fagan, W. F., Mueller, T., Olson, K. A., Leimgruber, P., and Calabrese, J. M. (2015). Rigorous home range estimation with movement data: a new autocorrelated kernel density estimator. Ecology 96, 1182-1188. doi: 10.1890/14-2010.1

Fleming, C. H., Fagan, W. F., Mueller, T., Olson, K. A., Leimgruber, P., and Calabrese, J. M. (2016). Estimating where and how animals travel: an optimal framework for path reconstruction from autocorrelated tracking data. Ecology 97, 576 - 582. doi: 10.1890/15-1607

Freemantle, T. P., Wacher, T., Newby, J., and Pettorelli, N. (2013). Earth observation: overlooked potential to support species reintroduction programmes. Afr. J. Ecol. 51, 482-492. doi: 10.1111/aje.12060

Gilbert, T. (2010). International Studbook for the Scimitar-Horned Oryx, Oryx Dammah. Winchester: Marwell Wildlife.

Gillet, H. (1965). L'oryx algazelle et l'addax au TChad. Revue d'écologie 3, 257-272.
Godefroid, S., Piazza, C., Rossi, G., Buord, S., Stevens, A. D., Aguraiuja, R., et al. (2011). How successful are plant species reintroductions? Biol. Conserv. 144, 672-682. doi: 10.1016/j.biocon.2010.10.003

Gorelick, N., Hancher, M., Dixon, M., Ilyushchenko, S., Thau, D., and Moore, R. (2017). Google earth engine: planetary-scale geospatial analysis for everyone. Remote Sens. Environ. 202, 18-27. doi: 10.1016/j.rse.2017.06.031

Griffith, B., Scott, J. M., Carpenter, J. W., and Reed, C. (1989). Translocation as a species conservation tool: status and strategy. Science 245, 477-480. doi: $10.1126 /$ science. 245.4917 .477

Gurarie, E., and Ovaskainen, O. (2011). Characteristic spatial and temporal scales unify models of animal movement. Am. Nat. 178, 113-123. doi: 10.1086/660285

Hamilton, L. P., Kelly, P. A., Williams, D. F., Kelt, D. A., and Wittmer, H. U. (2010). Factors associated with survival of reintroduced riparian brush rabbits in California. Biol. Conserv. 143, 999-1007. doi: 10.1016/j.biocon.2010.01.015

Harris, G., Thirgood, S., Hopcraft, J. G. C., Cromsigt, J. P., and Berger, J. (2009). Global decline in aggregated migrations of large terrestrial mammals. Endanger. Species Res. 7, 55-76. doi: 10.3354/esr00173

Hester, J. M., Price, S. J., and Dorcas, M. E. (2008). Effects of relocation on movements and home ranges of eastern box turtles. J. Wildlife Manage. 72, 772-777. doi: 10.2193/2007-049

Hilton-Taylor, C. (2000). 2000 IUCN Red List of Threatened Species. IUCN, Gland, Switzerland and Cambridge, UK.

Horne, J. S., Garton, E. O., Krone, S. M., and Lewis, J. S. (2007). Analyzing animal movements using Brownian bridges. Ecology 88, 2354-2363. doi: 10.1890/06-0957.1

IUCN SSC Antelope Specialist Group (2017). Gazella dorcas. The IUCN Red List of Threatened Species 2017: e.T8969A50186334.

Iyengar, A., Gilbert, T., Woodfine, T., Knowles, J. M., Diniz, F. M., Brenneman, R. A., et al. (2007). Remnants of ancient genetic diversity preserved within captive groups of scimitar-horned oryx (Oryx dammah). Mol. Ecol. 16, 2436-2449. doi: 10.1111/j.1365-294X.2007.03291.x

Janson, C. H. (1998). Experimental evidence for spatial memory in foraging wild capuchin monkeys, Cebus apella. Anim. Behav. 55, 1229-1243. doi: 10.1006/anbe.1997.0688

Johnson, D. S., London, J. M., Lea, M. A., and Durban, J. W. (2008). Continuoustime correlated random walk model for animal telemetry data. Ecology 89, 1208-1215. doi: 10.1890/07-1032.1

Kacem, S., Müller, H.-P., and Wiesner, H. (1994). Gestion de la faune sauvage et des parcs nationaux en Tunisie. Eschborn: Réintroduction, gestion et aménagement.

Kemp, L., Norbury, G., Groenewegen, R., and Comer, S. (2015). “Chapter: 7: The roles of trials and experiments in fauna reintroduction programs," in Advances in Reintroduction Biology of Australian and New Zealand Fauna, eds D. P. Armstrong, M. W. Hayward, D. Moro, and P. J. Seddon (Collingwood, VIC: CSIRO Publishing), 73-90.

Little, H. A., Gilbert, T. C., Athorn, M. L., and Marshall, A. R. (2016). Evaluating conservation breeding success for an extinct-in-the-wild antelope. PLoS ONE 11:e0166912. doi: 10.1371/journal.pone.0166912

Mihoub, J. B., Robert, A., Le Gouar, P., and Sarrazin, F. (2011). Post-release dispersal in animal translocations: social attraction and the "Vacuum Effect." PLoS ONE 6:e27453. doi: 10.1371/journal.pone.0027453

Moehrenschlager, A., and Macdonald, D. W. (2003). Movement and survival parameters of translocated and resident swift foxes Vulpes velox. Anim. Conserv. 6, 199-206. doi: 10.1017/S1367943003251

Morrow, C., Molcanova, R., and Wacher, T. (2013). “Oryx dammah, scimitarhorned oryx," in Mammals of Africa, ed J. Kingdon (London: Bloomsbury Publishing), 586-592.

Morrow, C. J., Wildt, D. E., and Monfort, S. L. (1999). Reproductive seasonality in the female scimitar-horned oryx (Oryx dammah). Anim. Conservat. Forum 2, 261-268. doi: 10.1111/j.1469-1795.1999.tb00072.x

Muths, E., and Dreitz, V. J. (2008). Monitoring programs to assess reintroduction efforts: a critical component in recovery. Anim. Biodivers. Conserv. 31, 47-56. Available online at: https://scholarworks.umt.edu/wildbio_pubs/55

Newby, J. (1978). Scimitar-horned oryx - the end of the line? Oryx 14, 219-221. doi: $10.1017 /$ S0030605300015520

Newby, J. (1980). Can addax and oryx be saved in the Sahel? Oryx 15, 262-266. doi: $10.1017 /$ S0030605300024662 
Newby, J. (1988). "Aridland wildlife in decline: the case of the scimitar-horned oryx," in Conservation and Biology of Desert Antelopes, eds A. Dixon and D. Jones(London: Christopher Helm), 146-166.

Newby, J., Wacher, T., Durant, S. M., Pettorelli, N., and Gilbert, T. (2016). "Desert antelopes on the brink: how resilient is the Sahelo-Saharan ecosystem?" in Antelope Conservation: From Diagnosis to Conservation, eds J. Bro-Jørgensen and D. Mallon (Chichester: Wiley Blackwell), 253-279. doi: 10.1002/9781118409572.ch13

Newby, J., Wacher, T., Lamarque, F., Cuzin, F., and de Smet, K. (2008). Nanger dama. The IUCN Red List of Threatened Species 2008: e.T8968A12941085.

Parker, I. D., Watts, D. E., Lopez, R. R., Silvy, N. J., Davis, D. S., McCleery, R. A., et al. (2008). Evaluation of the efficacy of Florida Key deer translocations. J. Wildlife Manage. 72, 1069-1075. doi: 10.2193/2007-025

Pettorelli, N., Ryan, S., Mueller, T., Bunnefeld, N., Jedrzejewska, B., Lima, M., et al. (2011). The Normalized Difference Vegetation Index (NDVI): unforeseen successes in animal ecology. Clim. Res. 46, 15-27. doi: 10.3354/cr00936

Polansky, L., Kilian, W., and Wittemyer, G. (2015). Elucidating the significance of spatial memory on movement decisions by African savannah elephants using state-space models. Proc. R. Soc. B Biol. Sci. 282:20143042. doi: $10.1098 /$ rspb.2014.3042

Popp, J. N., Toman, T., Mallory, F. F., and Hamr, J. (2014). A century of Elk restoration in eastern North America. Restorat. Ecol. 22, 723-730. doi: $10.1111 /$ rec. 12150

Pozdnyakov, V., Meyer, T., Wang, Y. B., and Yan, J. (2014). On modeling animal movements using Brownian motion with measurement error. Ecology 95, 247-253. doi: 10.1890/13-0532.1

R Core Team (2016). R: A Language and Environment for Statistical Computing. Vienna.

Rittenhouse, C. D., Millspaugh, J. J., Hubbard, M. W., and Sheriff, S. L. (2007). Movements of translocated and resident three-toed box turtles. J. Herpetol. 41, 115-121. doi: 10.1670/0022-1511(2007)41[115:MOTART]2.0.CO;2

Ryckman, M. J., Rosatte, R. C., McIntosh, T., Hamr, J., and Jenkins, D. (2010). Postrelease dispersal of reintroduced Elk (Cervus elaphus) in Ontario, Canada. Restorat. Ecol. 18, 173-180. doi: 10.1111/j.1526-100X.2009.00523.x

Sarmento, P., Carrapato, C. A., Eira, C. A., and Silva, J. P. (2017). Spatial organization and social relations in a reintroduced population of Endangered Iberian lynx Lynx pardinus. Oryx 53, 344-355. doi: $10.1017 /$ S0030605317000370

Sarrazin, F., and Barbault, R. (1996). Reintroduction: challenges and lessons for basic ecology. Trends Ecol. Evol. 11, 474-478. doi: 10.1016/0169-5347(96)20092-8

Schlägel, U. E., and Lewis, M. A. (2014). Detecting effects of spatial memory and dynamic information on animal movement decisions. Methods Ecol. Evol. 5, 1236-1246. doi: 10.1111/2041-210X.12284

Schmitz, P., Caspers, S., Warren, P., and Witte, K. (2015). First steps into the wild - exploration behavior of European bison after the first reintroduction in Western Europe. PLoS ONE 10:e0143046. doi: 10.1371/journal.pone.0143046

Scillitani, L., Sturaro, E., Menzano, A., Rossi, L., Viale, C., and Ramanzin, M. (2012). Post-release spatial and social behaviour of translocated male Alpine ibexes (Capra ibex ibex) in the eastern Italian Alps. Eur. J. Wildl. Res. 58, 461-472. doi: 10.1007/s10344-011-0596-9

Seddon, P. J. (1999). Persistence without intervention: assessing success in wildlife reintroductions. Trends Ecol. Evol. 14, 503. doi: 10.1016/S0169-5347(99)01720-6

Seddon, P. J., Armstrong, D. P., and Maloney, R. F. (2007). Developing the science of reintroduction biology. Conservat. Biol. 21, 303-312. doi: 10.1111/j.1523-1739.2006.00627.x

Shannon, J. M., Olson, D. D., Whiting, J. C., Flinders, J. T., and Smith, T. S. (2008). "Status, distribution, and history of Rocky Mountain bighorn sheep in Utah," in Proceedings of the Northern Wild Sheep and Goat Council, Vol. 16, (Midway, UT), 178-195.

Sheean, V. A., Manning, A. D., and Lindenmayer, D. B. (2012). An assessment of scientific approaches towards species relocations in Australia. Austral Ecol. 37, 204-215. doi: 10.1111/j.1442-9993.2011.02264.x

Stabach, J. A., Rabeil, T., Turmine, V., Wacher, T., Mueller, T., and Leimgruber, P. (2017). On the brink of extinction-Habitat selection of addax and dorcas gazelle across the Tin Toumma desert, Niger. Divers. Distribut. 23, 581-591. doi: 10.1111/ddi.12563

Stamps, J. A., Krishnan, V. V., and Reid, M. L. (2005). Search cost and habitat selection by dispersers. Ecology 86, 510-518. doi: 10.1890/04-0516

Stamps, J. A., and Swaisgood, R. R. (2007). Someplace like home: experience, habitat selection and conservation biology. Appl. Anim. Behav. Sci. 102, 392-409. doi: 10.1016/j.applanim.2006.05.038

Sutherland, W. J., Armstrong, D., Butchart, S. H. M., Earnhardt, J. M., Ewen, J., Jamieson, I., et al.. (2010). Standards for documenting and monitoring bird reintroduction projects. Conservat. Lett. 3, 229-235. doi: 10.1111/j.1755-263X.2010.00113.x

Taylor, G., Canessa, S., Clarke, R. H., Ingwersen, D., Armstrong, D. P., Seddon, P. J., et al. (2017). Is reintroduction biology an effective applied science? Trends Ecol. Evol. 32, 873-880. doi: 10.1016/j.tree.2017.08.002

Teixeira, C. P., De Azevedo, C. S., Mendl, M., Cipreste, C. F., and Young, R. J. (2007). Revisiting translocation and reintroduction programmes: the importance of considering stress. Anim. Behav. 73, 1-13. doi: 10.1016/j.anbehav.2006.06.002

Tollington, S., Greenwood, A., Jones, C. G., Hoeck, P., Chowrimootoo, A., Smith, D., et al. (2015). Detailed monitoring of a small but recovering population reveals sublethal effects of disease and unexpected interactions with supplemental feeding. J. Anim. Ecol. 84, 969-977. doi: $10.1111 / 1365-2656.12348$

Tuberville, T. D., Norton, T. M., Todd, B. D., and Spratt, J. S. (2008). Longterm apparent survival of translocated gopher tortoises: a comparison of newly released and previously established animals. Biol. Conserv. 141, 2690-2697. doi: $10.1016 /$ j.biocon.2008.08.004

Uhlenbeck, G. E., and Ornstein, L. S. (1930). On the theory of the Brownian motion. Phys. Rev. 36:823. doi: 10.1103/PhysRev.36.823

Van Winkle, W. (1975). Comparison of several probabilistic home-range models. J. Wildlife Manag. 39, 118-123. doi: 10.2307/3800474

Vermote, E. (2015). MOD09Q1 MODIS/Terra Surface Reflectance 8-Day L3 Global 250m: V006. NASA EOSDIS Land Processes DAAC 10.

Winner, K., Noonan, M. J., Fleming, C. H., Olson, K. A., Mueller, T., Sheldon, D., et al. (2018). Statistical inference for home range overlap. Methods Ecol. Evol. 9 , 1679-1691. doi: 10.1111/2041-210X.13027

Wolf, C. M., Griffith, B., Reed, C., and Temple, S. A. (1996). Avian and mammalian translocations: update and reanalysis of 1987 survey data. Conservat. Biol. 10, 1142-1154. doi: 10.1046/j.1523-1739.1996.10041142.x

Wood, S. N. (2011). Fast stable restricted maximum likelihood and marginal likelihood estimation of semiparametric generalized linear models. J. R. Stat. Soc. Ser. B 73, 3-36. doi: 10.1111/j.1467-9868.2010.00749.x

Woodfine, T., and Gilbert, T. (2016). "The fall and rise of the scimitar-horned oryx: a case study of ex-situ conservation and reintroduction in practice," in Antelope Conservation: From Diagnosis to Action, eds J. Bro-Jørgensen and D. Mallon (Chichester: Wiley Blackwell), 280-296. doi: 10.1002/97811184095 72.ch14

Yoder, J. M., Marschall, E. A., and Swanson, D. A. (2004). The cost of dispersal: predation as a function of movement and site familiarity in ruffed grouse. Behav. Ecol. 15, 469-476. doi: 10.1093/beheco/arh037

Yott, A., Rosatte, R., Schaefer, J. A., Hamr, J., and Fryxell, J. (2011). Movement and spread of a founding population of reintroduced Elk (Cervus elaphus) in Ontario, Canada. Restorat. Ecol. 19, 70-77. doi: 10.1111/j.1526-100X.2009.00639.x

Conflict of Interest: The authors declare that the research was conducted in the absence of any commercial or financial relationships that could be construed as a potential conflict of interest.

Copyright (๑) 2019 Mertes, Stabach, Songer, Wacher, Newby, Chuven, Al Dhaheri, Leimgruber and Monfort. This is an open-access article distributed under the terms of the Creative Commons Attribution License (CC BY). The use, distribution or reproduction in other forums is permitted, provided the original author(s) and the copyright owner(s) are credited and that the original publication in this journal is cited, in accordance with accepted academic practice. No use, distribution or reproduction is permitted which does not comply with these terms. 